\title{
SEXUAL EDUCATION OF INDIVIDUALS WITH MULTIPLE DISABILITIES: THEORETICAL-METHODOLOGICAL ASPECT
}

\author{
D. Georgieva* \\ Faculty of Education, Trakia University, Stara Zagora, Bulgaria
}

\begin{abstract}
The sexual education of individuals with multiple disabilities holds a special place in the contemporary content of the subject of Special Education. The article is dedicated to the theoretical and methodological aspects of the discussed problem. The conceptual thesaurus of the presented thematic area is highlighted. Special attention is paid to the stages of human psychosexual development and the regularities of pubertal maturation. The main focus is placed on the sexual self-determination of the young people with intense and complex combinations of disabilities, the equal rights and conditions of functioning within the range of the opportunities available. The principles underlying the approach to the care of persons with multiple physical and mental limitations in the field of their sexual education are presented. There is a particular interest in the current and delicate problematic, which addresses the importance and conditions of sexual education for the development of sexuality, as well as the parents' attitudes towards the sexual relations of their children. An attempt has been made to identify the main areas of activity related to supporting people with multiple disabilities in finding their own way in the field of sexuality and partnership.
\end{abstract}

Key words: sexuality, sexual education, individuals with multiple disabilities, psychosexual development

\section{INTRODUCTION}

Sexual education of individuals with multiple disabilities occupies a special place in the modern content of the subject of Special Education. The actuality of the problem is determined mainly by the need to supplement the fragmentary research related to the content and specifics of sex education in this category of individuals. Sexual education is considered an important component of the whole process of personality education. In this process, knowledge and skills are formed for the respective gender to which the child belongs.

The current stage of society development is characterized by the opinion (formed over a long period of time) about the non-existent differences between people with disabilities and people with typical development in terms of sexuality, which is based on principles common to both groups.

Correspondence to: Diyana Paskaleva Georgieva Faculty of Education, Trakia University

Stara Zagora, Bulgaria, paskaldi1929@abv.bg
Naturally and logically, the topicality and the need to study this problem stem from the widespread dissemination of the normalization principle implemented in all areas, including in the field of sexual self-determination of young people with atypical development. The principle postulates the human right to autonomous sexuality - an article enshrined in The UN Declaration of Human Rights with Intellectual Disabilities.

The existence of "secondary social constraints" created on the basis of prejudice and manifesting as additional barriers to the wellbeing of these individuals also conditions the importance of the problem. Unfortunately, many people are not able to accept the presence of sexual life in a person with psycho-physical limitations. At the same time, the stereotype that people with multiple disabilities are more likely to make mistakes or suffer sexual perversions than other people is increasingly being refuted. 
Last but not least, the consideration and revision of the issue of sexuality in individuals with disabilities justifies the increased interest in the current topic. The publication of scientific materials would allow specialists to expand their understanding of the sexuality of young people with multiple disabilities.

\section{LITERATURE REVIEW}

\section{Conceptual thesaurus of the presented thematic area}

Children with multiple disabilities are a special category characterized by the coexistence of more than one disorder in physical and/or psychological development.

Gender is considered from different positions: biological, psychological, pedagogical. From this point of view, gender is a biosocial property of human [1]. In the context of the pedagogical position, sex education is carried out in the process of his sexual socialization.

Sexual socialization is a process involving the acquisition of social experience related to gender; the reproduction of the individual systems of the relationships between the sexes in active work [2]. Gender socialization contains 3 components: development of the image of oneself as a representative of the respective gender; an occurrence of gender role preferences and value orientations; behavior patterns relevant to gender. Leading mechanisms of gender socialization are gender identification and gender differentiation.

Gender identification, which largely determines the "I-concept", is defined as the identification of oneself with the representatives of the sexes, manifested in the unity of behavior and self-consciousness of the individual who assigns him/herself to the respective sex and is oriented to the requirements for the concrete gender role [3].

Gender differentiation is the definition of oneself as a representative of the respective sex manifested in an aggregation of genetic, morphological, physiological traits, on the basis of which the two sexes differ.

Sex education is studied in different aspects: sexological, medical, psychological, social, ethical, physiological, and pedagogical [3]. In a broad sense, it is accepted as an influence of the environment on the psychosexual development and formation of the individual. In the narrow sense of the word - systematic, consciously planned support related to
GEORGIEVA D.

psychological and physical development of boys/girls, aimed at optimizing their personal development and functioning in all spheres of life related to gender relationships. An important part of sex education is sex enlightenment. It is a system of ways of informing, disseminating knowledge about the physiology and psychology of gender, psychosexual processes and relationships. Closely related to this concept are the concepts of "sexuality" and "sex cultivation". Sexuality is what distinguishes a man from a woman in a biological context. It is inherent to every individual, including people with disabilities. Sex cultivation in a broad sense is defined as the functioning of a person in the role of a man or a woman. In the narrow sense of the word it means the formation of sexual-erotic orientations, sexual consciousness and behavior in the context of psychosexual culture: awareness of one's own gender, sex differentiation, assimilation of gender role models, satisfaction of gender needs, assimilation of social roles.

\section{The problem of sexuality in people with multiple disabilities}

In terms of sexuality, there are no differences between people with disabilities and people with typical development. Sexuality is based on principles that are common to both groups. This opinion is characteristic of the modern stage of development of society and has been forming in the process of a long period of social development. In the 1950s, the principle of normalization became widespread. It has been realized in all areas, including in the field of sexual self-determination of persons with disabilities and which postulates the right to autonomous sexuality. This situation is enshrined in the document of international importance: The UN Declaration of Human Rights with Intellectual Disabilities. Despite this declaration, in the 1970s the efforts of the educationalists were aimed at preventing and distracting people with intellectual disabilities from their sexual desires $[4,5]$.

Accommodation people with physical and (or) mental disabilities in special institutions has been considered the best form of sexual prevention. The history of sex education/cultivation for young people with disabilities is linked to the history of sexual repression. There has been a prejudice that once "awakened" sexuality could become an uncontrollable phenomenon [6]. Sexuality for 
people with disabilities has been a forbidden field. The results of studies conducted in the late 70 's. in European countries lead to the conclusion that the people sexuality with intellectual disabilities and their sexual behavior depend primarily on the acceptance level of moral attitudes and prohibitions of their parents, as well as teachers and educationalists [7]. These studies demonstrate "secondary social constraints", which most often manifest themselves as additional barriers to the well-being of individuals with limits. The barriers, created on the basis of prejudice and conditioned by the difficult living conditions in the family, school or boarding school, contribute to the restriction of their sexuality deprived of the possibility of manifestation.

Striving for consistent implementation of the Scandinavian principle of normalization in Western European countries in the early 80's led to a rethinking and revision of the issue of sexuality in young people with limits. International congresses provide scientific materials that allow special educators to expand their understanding of the young people sexuality with multiple disabilities $[8$, 9].

Sexuality of these children is considered not as their problem, but mainly as a problem of their social environment (teachers, clinicians, parents, educators). In modern society there is still a tendency to accept citizens with mental disorders as passive subjects who cannot fully participate in society. These young people have difficulty answering questions: how and where they want to live, work and spend their free time. Therefore, parents and employees in the various educational and rehabilitation departments where children with disabilities are trained create certain conditions that contribute to improving the students life quality: good self-esteem, realization of feelings such as happiness, security, recognition and acceptance of their needs, empathy.

In recent years, more and more people in Western countries and in our country are realizing the need to accept the fact that, like people with typical development, people with limits have the same rights to develop their own sexuality. The results of research show that the sexual development of people with disorders in most cases is carried out in accordance with age norms [10]. It does not depend on the level of intelligence and there are no serious differences from the sexuality development of people without psychophysical restrictions.

Consequently, the beginning of puberty in young people with multiple disabilities corresponds to a certain age, but does not coincide with intellectual age: adults usually have normally developed genitals (even in cases of severe intellectual impairment) and reach puberty in accordance with the general standards of physical development. The cases of lack of sexual sexuality are rare and they are often a result of the socialization conditions. Increased and in some cases uncontrolled impulsivity and related deviations in the sexual behavior of people with multiple disabilities is a more common phenomenon, often causing confusion and fear in people around them.

Unfortunately, many people are not able to accept the presence of sexual life in a person with psycho-physical limitations. The question immediately arises as to how one cannot accept what is considered the absolute norm. The sexual actions of such people should not be seen solely as bodily satisfaction of physiological instinct. They are able to satisfy their sexual desires in a socially acceptable way personally. Empirical research refutes the stereotype that people with multiple disabilities are more likely to make mistakes or suffer sexual perversions than other people [11].

\section{Stages of psychosexual development in humans and the standard of puberty}

Sex education is carried out taking into account the peculiarities of human sexual development and the basic norms of sexual maturation. According to researchers, there are 7 stages of psychosexual development, covering a person's life from birth to old age [2]:

- prenatal (from conception to birth) formation of sex at the genetic, morphological level and brain structures responsible for sexual behavior;

- parapubertal (1-7 years) - formation of sexual self-awareness and gender identity;

- prepubertal (7-13 years) - formation of the stereotype of gender-role behavior, intensive socialization of the child is performed, the adequate gender-role behavior of the parents is of great importance; 
- pubertal (13-18 years) - formation of psychosocial orientation, the period is characterized by adolescent hypersexuality, having an experimental nature;

- transient (18-26) - a need and an ability for intimate psychological, including sexual intimacy with the other person;

- mature sexuality (25-56) - regular sexual activity;

- involutionary (over 55 years) - decreased interest in the sexual sphere.

\section{Development of sexuality in adolescence in individuals with intense and complex combinations of disorders}

Sexuality is formed at birth and depends on how the child's parents and relatives communicate with him/her and what their value system is [7]. For the formation of healthy sexuality it is necessary for the child to be guided from leading positions: "I am loved"; "I am a desired child"; "My body belongs to me". During the period under review, adolescents with disabilities had fewer opportunities to experiment than their typically developing peers. However, emotional, physical and social changes all manifest in the same form [12]. The emotional changes are often more difficult for adolescents with multiple disabilities to experience because their sexual interest in others is usually strongly rejected and the parents avoid talking about sexual matters. This is why the young people with disabilities feel lonely and rejected in such situations. The typical states of frequent mood swings are even more pronounced. Often teenagers are not prepared for the changes that occur with their body, which is why they are characterized by various behavioral disorders. In most cases, adolescents experience some negativity towards themselves, which can subsequently lead to severe depression [13]. Thus, the process of raising children with multiple disabilities is accompanied by certain difficulties.

The results of the studies show that the hormone levels of young men and women with Down syndrome and their peers with typical development differ slightly $[14,15]$. A child with intellectual limits also experiences a hormonal attack when enter the stage of puberty, which is why the parents must create a freer living space. The emotional and physical closeness of the child with the parents can be perceived by them as something
GEORGIEVA D.

unpleasant. However, the parents need to understand that in this way the teenager is trying to break free from "the parent-child relationship". The children with multiple disabilities go through this period in different ways. If a teenager with limits is provided with his/her own intimate space, he/she will form an adequate sense of how to behave, which will allow the formation of the ability to make decisions in a social and sexual context.

\section{Sexual self-determination of the category of persons concerned, including equal rights and equal conditions of functioning within the range of opportunities}

Equal rights and equal conditions of functioning within the scope of the possibilities are presented in two dimensions: individual sexual and intimate life and psychophysical inviolability and protection from sexual violence. The right to individual sexual and intimate life begins with self-determination of the intimate sphere in one's own room. Without personal space, it is impossible for a man to learn to set permissible limits for $\mathrm{him} /$ herself and recognize situations in which someone tries to violate them [16]. In this way, the lack of separate living rooms in institutions for people with disabilities reflects an extremely low standard in international practice and is defined as an expression of structural violence against the individual. Personal observations show that there are still cases when the staff of the institution does not accept the sexuality and sexual behavior of young people with multiple disabilities due to their own moral norms and attitudes. Regarding to the right to psychophysical safety and protection from sexual violence, it should be noted that young people with multiple limits, and especially women/girls, are often subject to sexual violence or harassment in private life. In these individuals from an early age the development of their own positive bodily experience is complicated [17]. Personal boundaries are no longer perceived, and it is difficult to relax their own intimate sphere. In this case, it is believed that people with mental disabilities have no idea of distance and experience alienation from their own body [18].

The most common causes of sexual violence are: (a) limited knowledge of sexuality (the children do not know the names of their own body); (b) lack of sexual experience; (c) nondifferentiation of feelings or impossibility to 
name them, non-awareness of the danger arising from other people; (d) inability to recognize violence, negative perception of one's own body and one's own significance; (e) residence in restricted conditions where there is no access to the content of concepts such as 'intimate area', 'intimate sphere'. These individuals do not perceive boundaries and experience significant difficulties in identifying, recognizing, expressing, and satisfaction their own needs [19].

Young people with multiple disorders due to the low degree of autonomy meet the requirements of other people; do not know how to say "no". And the more limited the sphere of influence of such a person, the less he/she is able to control the situation. There is a greater risk of sexual invasion. Sex education, which enables people with multiple disabilities to experience their own autonomous sexuality, is an effective protection and rational way to prevent violence.

The aims of sexual education include the following content: (a) Development of the sense of self-importance; (b) Training in the ability to share personal feelings without attempt of ignoring them; (c) Formation of experience for action in crisis situations; (d) Creating opportunities for sexual selfdetermination [2].

One of the main directions in the activity of the pedagogue-sexologist is the training of the young people with multiple disabilities in strategies for protection against potential sexual intrusion into their personal life [8]. Realization in this course is the basis of the knowledge transfer about the sexuality of this category of individuals and is important for the formation of self-awareness and selfdetermination in order to prevent sexual violence. As people with disabilities fall into the risk group of potential and actual victims of sexual violence, the work of the specialist includes the development of the positive aspects of the experienced sexuality and training in preventive protection measures.

The main areas of activity for the prevention of violence are related to the mastering of a system of rules that allow a more conscious perception of one's own feelings, emotions and actions.
The activity of the sexologist with people with multiple disabilities in terms of violence prevention takes the form of individual or group sessions aimed at strengthening the confidence of children, adolescents or adults in their own feelings, expanding the perimeter of their actions, explaining their rights [6].

Some employees of institutions for people with disabilities face a sexual-ethical and pedagogical dilemma related to sexuality issues: they refrain from any expression of their own opinion or pedagogical intervention; do not respond to the problem; they do not notice the problem or tolerate what is happening. Such a reaction creates a precondition for sexual "exploitation" of weaker people with disabilities in their group or in the institution where they live. In addition, it is necessary to take into account the fact that young people with intellectual limits cannot be independent and often follow the instructions and orders of others. This characteristic determines their inability to actively oppose acts of violence and increases the likelihood of violence against them. Therefore, in order to prevent violence, in parallel with effective sex education, it is necessary to develop the ability to recognize the danger by young people with multiple disabilities, the skill to say "no" and to turn to other people for help [12].

\section{Parents' attitudes towards their children's sexual relationships}

Parents often believe that possible infertility in their child will solve all the problems of his sex life [20,21].

Unfortunately, in the family and the school there is not always a purposeful activity on the sexual education of children, adolescents and adults with multiple disorders. This is the reason why these people do not understand the relation between conception and contraceptive protection and are not able to realistically assess the abuser's intentions and sexual actions.

Sexual education is considered as an important component of the whole process of personality education, which should begin at an early age [3]. When working with children and adolescents with multiple disabilities, it is unacceptable to use the rule "Wait until the child asks and give an answer that will not be followed by new questions". Such an approach is also unacceptable for adults who also do not 
ask questions "about it" and do not know how to express their feelings. This means that an individual approach is needed in sexual education.

Parents, teachers in special schools and staff in institutions must be able to explain the purpose of contraception or demonstrate a specific exercise on the use of these devices [9]. Sustainable sexual behavior can be nurtured through systematic exercise and practical use of contraceptives [15]. Lack or inadequacy of sex education causes insecurity, discomfort and helplessness in this important area of life, which can lead to seduction or the manipulation of an individual with limited capacity for personal gain. Consequently, the ultimate goal of sex education in young people with multiple disabilities is to prevent the often tragic isolation from society by building trust and self-confidence, as well as recognizing their human needs. As a result of this purposeful activity, it is possible for children and adolescents with disabilities to accept their own body, their own desires and opportunities in terms of partnership and sexuality in general [19].

Principles based on the approach to the care of individuals with multiple physical and mental disabilities in the field of their sexual education

- Principle of normalization. Normalization means that people with disabilities interact with a partner of the opposite or their own sex have a sexual experiences and express their sexual feelings, use dedicated public institutions located near the home. Properly organized sex education is aimed at recognizing and satisfying one's own needs and ensuring the normalization of the living conditions of these young people;

- Principle of integration. The principle provides the acceptance of the individual with disorders as a full member of society, taking into account his/her peculiarities and his/her recognition as a partner;

- Principle of emancipation. It is postulated to strengthen the sense of selfimportance. It is necessary to take into consideration the ability of each person to perform independently what he/she is capable of. Professional support in this case is considered as an adjunct to independence. Independence to a large extent develops a certain sense of responsibility in the individual with a disability;
- Principle of acceptance. To a large extent, the lives of these people are directly dependent on the beliefs and attitudes of people close to them. Positive attitudes are expressed in: ability and willingness to penetrate the world of another's personal experience; a willingness to understand the meaning of what one expresses or tries to express through one's behavior; a readiness to know the biography of another person; readiness desire and ability to care for another human.

Conditions of sex education for the development of sexuality

The need for sex education for young people with disabilities is determined by the risk of antisocial acts and sexual harassment, unwanted pregnancy during sexual contacts, the dander of transmitting AIDS. The results of recent studies show that the level of this autoimmune disease in these individuals doubles every 1 year and 10 months [22]. Children with many psychophysical difficulties need certain independence under specific conditions. It is appropriate to talk to them as adults, avoiding children's words, to control the way adolescents dress according to their age. If a teenager is allowed to behave like a child, he/she will use this cliché of the "eternal child" [2]. The process of sex education involves the sexuality development, which in turn is related to the development of gender identity. If sexuality is denied, then the teenager will not be able to accept his own bodily and physical changes. He/she will have difficulty forming a positive image of $\mathrm{him} / \mathrm{herself}$ as a growing man/woman.

With the wrong attitudes in the family, school or center, the sexuality of young people with disabilities becomes limited sexuality or does not manifest itself at all. In this context, researchers point out conditions for optimal development of sexuality [10]:

- providing intimate space;

- providing initial information about the structure and functions of the human body, the periods of psycho-social development and the resulting changes; for the type of sexuality, and for protection from sexual violence;

- support in finding a partner - young people have great difficulty finding a sexual partner;

- tolerating the choice of a partner - many young men with disabilities are attracted to 
a partner of the same sex like people with typical development.

\section{CONCLUSION}

Sexuality is inherent in every person, and consideration of gender affiliation shows that it is an integral part of gender identity. If the aspiration and desires for love, tenderness and eroticism are ignored, then the individual with many psychophysical limitations is isolated from his/her problem. His/her right to lead a prosperous life is violated.

This theoretical study has confirmed that the sexual needs, desires and problems of young people with disabilities do not differ significantly from the sexuality of individuals with typical development. People with disabilities face serious barriers due to the existing stigmas on the part of society, which generates certain obstacles to the normal functioning of life. The sexuality of adolescents with different combinations of disorders is a problem not only for them but also for the people around them, whose behavior; moral and ethical attitudes condition the opportunities and chances of these young people to have a normal sex life.

The solution to the problem lies in the optimal conduct of the process of sex education.

\section{REFERENCES}

1. Weis, D. L. (1998). The state of sexology, Journal of Sex Research, 35 (1).

2. Kon, I. S. (2004). Sexology, Academa, M.

3. Pownall, J. D., Jahoda, A., Hastings, R. P. (2012). Sexuality and sex education of adolescents with intellectual disability: Mothers' attitudes, experiences, and support needs. Intellectual and Developmental Disabilities, 50 (2), 140-154.

4. Bender, M. P., Aitman, J. B., Biggs, S. J., \& Haug, U. (1983). Initial findings concerning a sexual knowledge questionnaire, Journal of the British Institute of Mental Handicap, 11 (4), 168-169.

5. Brantlinger, E. A. (1985). Mildly mentally retarded secondary students' information about and attitudes toward sexuality and sexuality education. Education \& Training of the Mentally Retarded, 20, 99-108.

6. Evans, D. S., McGuire, B. E., Healy, E. \& Carley, S. N. (2009). Sexuality and Personal Relationships for People with Intellectual Disability, Part II: Staff and Family Carer Perspectives, Journal of
GEORGIEVA D.

Intellectual Disability Research, 53 (11), 913-921.

7. Cuskelly, M., \& Bryde, R. (2004). Attitudes towards the sexuality of adults with an intellectual disability: Parents, support staff, and a community sample, Journal of Intellectual \& Developmental Disability, 29 (3), 255-264.

8. McCann, E., Donohue, G., de Jager, J., Nugter, A., Stewart, J., \& Eustace-Cook, J. (2019). Sexuality and intimacy among people with serious mental illness: A qualitative systematic review, JBI Database of Systematic Reviews and Implementation Reports, 17 (1), 74-125.

9. Talbot, T. J., Langdon (2006). A revised sexual knowledge assessment tool for people with intellectual disabilities: Is sexual knowledge related to sexual offending behavior? Journal of Intellectual Disability Research, 50 (7), 523-531.

10.Hingsburger, D., \& Tough, S. (2002). Healthy sexuality: Attitudes, systems, and policies, Research \& Practice for Persons with Severe Disabilities, 27 (1), 8-17.

11.Cheng, Z. \& Smyth, R. (2015). Sex and Happiness, Journal of Economic Behavior and Organization ,112, 26-32.

12.Cheng, M. M., \& Udry, J. R. (2005). Sexual experiences of adolescents with low cognitive abilities in the US. Journal of Developmental and Physical Disabilities, 17 (2), 155-172.

13.Lindsay, W. R. \& Lees, M. S. (2003). A comparison of anxiety and depression in sex offenders with intellectual disability and a control group with intellectual disability, Sex Abuse, 15, 339-345.

14.Zuhlke, C., Thies, U. \& Braulke I. (1994). Down syndrome and male fertility: PCRderived fingerprinting, serological and andrological investigations, Clinical Genetics, 46, 324-326.

15.Goldstein, H. (1988). Menarche, menstruation, sexual relations and contraception of adolescent females with Down syndrome, European Journal of Obstetrics \& Gynecology and Reproductive Biology, 27, 343-349.

16. Shuttleworth, R. P. (2007). Critical research and policy debates in disability and sexuality studies. Sexuality Research \& Social Policy, 4 (1), 1-14.

17.Vehmas, S. \& Watson, N. (2014). Moral Wrongs, Disadvantages, and Disability: A Critique of Critical Disability Studies, Disability \& Society 29 (4), 638-50. 
18.Fiduccia, B. W. (2000). Current issues in sexuality and the disability movement, Sexuality and Disability, 18 (3), 167-174.

19.Kafer, A. (2003). Compulsory Bodies: Reflections on Heterosexuality and Ablebodiedness, Journal of Women's History, 15 (3), 77-89.

20.Passer, A., Rauh, J. \& Chamberlain, A. (1984). Issues in fertility control for mentally retarded female adolescents: II.
GEORGIEVA D.

Parental attitudes toward sterilization, Pediatrics, 73, 451-454.

21.Pham, H. H., \& Lerner, B. H. (2001). In the patient's best interest? Revisiting sexual autonomy and sterilization of the developmentally disabled, Western Journal of Medicine, 175 (4), 280-283.

22.Meade, C. \& Sikkema, K. (2005). HIV risk behavior among adults with severe mental illness: a systematic review, Clinical Psychology Review, 25, 433-57. 